\title{
Higher oxygen saturation targets did not improve growth and neurodevelopment in extremely preterm infants
}

Askie LM, Henderson-Smart DJ, Irwig L, et al. Oxygen-saturation targets and outcomes in extremely preterm infants. N Engl J Med 2003;349:959-67.

\section{Does maintenance of higher oxygen saturation $\left(\mathrm{SpO}_{2}\right)$ targets $(95-98 \%)$ improve growth and neurodevelopment compared with standard targets $(91-94 \%)$ in extremely preterm infants dependent on supplemental oxygen?}

\section{METHODS:}

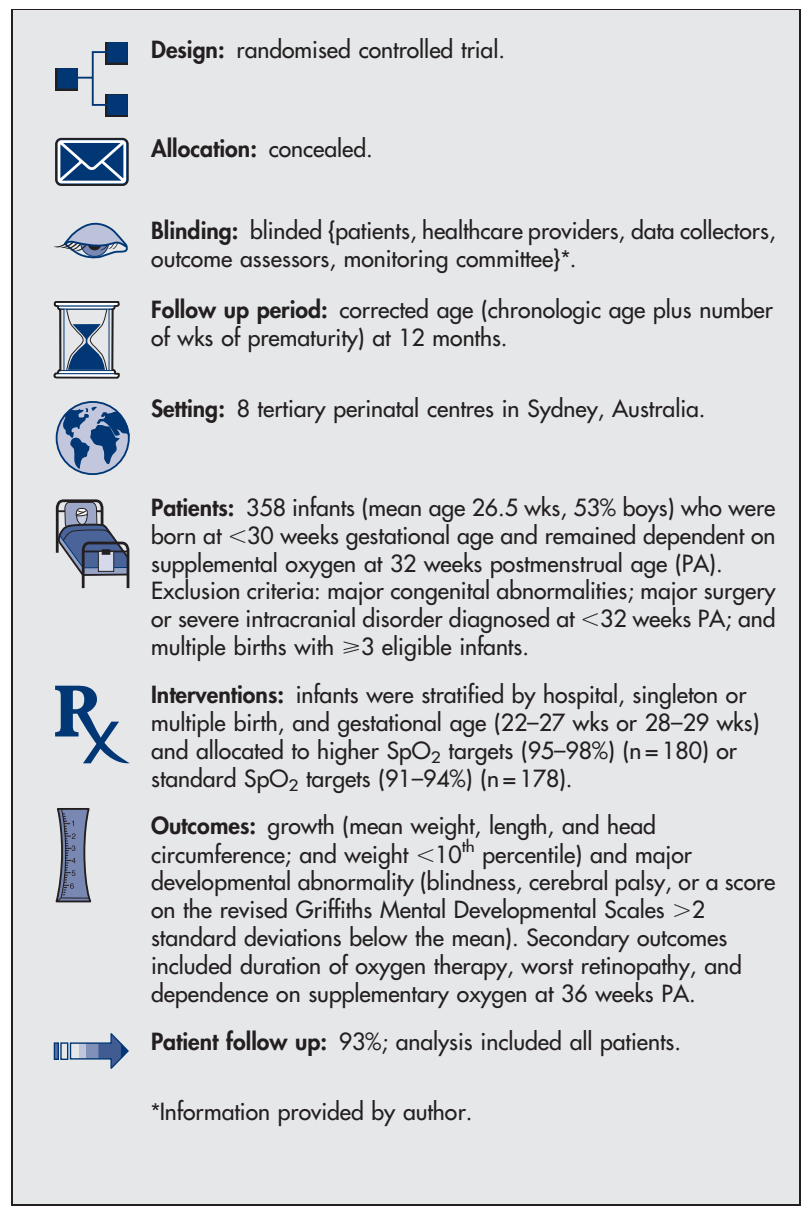

For correspondence: $\operatorname{Dr} \mathrm{L} M$ Askie, RN, University of Sydney, New South Wales, Australia. lisa.askie@perinatal.usyd.edu.au

Source of funding: National Health and Medical Research Council of Australia and Financial Markets Foundation for Children.

\section{MAIN RESULTS}

Analysis was by intention to treat. The groups did not differ for growth outcomes or major developmental abnormalities (table), or worst retinopathy $(\mathrm{p}=0.34)$. However, the higher target group had higher rates of dependence on supplemental oxygen at 36 weeks PA (table) and spent more days on oxygen (median $40 \vee 17.5 \mathrm{~d}$, $\mathrm{p}<0.001)$ than those in the standard target group.

\section{CONCLUSION}

In extremely preterm infants who are dependent on supplemental oxygen, maintenance of higher oxygen saturation targets (95-98\%) did not improve growth or neurodevelopment.

\section{Commentary}

ncreasingly, research is being done in neonatal intensive care units (NICUs) to examine clinical practices and oxygen saturation monitoring of premature infants. Most of these studies assess incidence and severity of retinopathy of prematurity (ROP) as a primary outcome. The study by Askie et al is one of the few studies that assess growth and neurodevelopmental outcomes. At 12 months corrected age, the groups did not differ for weight, length, head circumference, or frequency of major developmental abnormalities. In addition, Askie et al showed that the higher target group had increased dependence on supplemental oxygen and more days on oxygen but did not differ from the standard target group for worst ROP. However, NICUs can vary with respect to pulse oximetry monitoring. The target range used by Askie et al may differ from those used in other NICUs. The lower $\mathrm{SpO}_{2}$ target of $91 \%$ is higher than those reported by Chow et al, who used $\mathrm{SpO}_{2}$ targets of $85-$ $93 \%$ to evaluate the clinical practice of oxygen management and its effects on ROP. ${ }^{1}$ As well, the study by Askie et al may not have been large enough to detect a significant difference between groups for several adverse outcomes, such as worst ROP, as it was powered to find large differences between groups.

The results of this study may prompt neonatal nurses to evaluate the oxygen monitoring practices of their own nurseries. Although the optimal $\mathrm{SpO}_{2}$ range for extremely premature infants has not been identified, it appears that lower alarms settings (91-94\%) may have benefits for infants, such as less respiratory support, without compromising growth and neurodevelopment. As recent ROP research is using even lower oxygen saturations, it would be interesting to repeat this study using targets of $85-93 \%$.

$$
\begin{array}{r}
\text { Carol Botwinski, RNC, EdD(c), MS, ARNP } \\
\text { All Children's Hospital } \\
\text { St Petersburg, Florida, USA }
\end{array}
$$

\begin{tabular}{|c|c|c|c|c|}
\hline Outcomes at 12 months corrected age & Higher targets & Standard targets & \multicolumn{2}{|c|}{ Mean difference $(95 \% \mathrm{Cl})$} \\
\hline Weight (kg) & 9.25 & 9.10 & \multicolumn{2}{|c|}{$0.15(-0.2$ to 0.5$)$} \\
\hline Length $(\mathrm{cm})$ & 74.1 & 74.0 & \multicolumn{2}{|c|}{$0.1(-0.8$ to 1.0$)$} \\
\hline Head circumference $(\mathrm{cm})$ & 46.3 & 46.3 & \multicolumn{2}{|c|}{$0.0(-0.4$ to 0.4$)$} \\
\hline & & & RRR (Cl) & NNT \\
\hline Weight $<10^{\text {th }}$ percentile & $33 \%$ & $37 \%$ & \multirow{2}{*}{$\begin{array}{r}11.4 \%(-34 \text { to } 19) \\
3.7 \%(-34 \text { to } 41)\end{array}$} & Not significant \\
\hline Major developmental abnormality & $23 \%$ & $24 \%$ & & Not significant \\
\hline & & & RRI (Cl) & NNH (Cl) \\
\hline Dependence on supplemental oxygen at 36 wks PA & $64 \%$ & $46 \%$ & $40 \%(16$ to 70$)$ & $6(4$ to 13$)$ \\
\hline
\end{tabular}

1 Chow LC, Wright KW, Sola A, et al. Pediatrics 2003;111:339-45.

Higher oxygen saturation targets (95-98\%) v standard saturation targets (91-94\%) for extremely premature infants* 